\title{
The anode oxidation reaction in fuel cell: A DFT study
}

\author{
Chenqing Ye ${ }^{1,2}$, Yichun Xie ${ }^{1}$, Liping Zheng ${ }^{1}$, Yuxiang Lin ${ }^{1, *}$, Weixiang Guo ${ }^{1}$, Xueqiang Qi ${ }^{3}$ \\ ${ }^{1}$ Fujian Yanan Power Company Limited, Fujian Fuan Mindong Yanan Electrical Machine Company Limited, Ningde, Fujian 352100, \\ China \\ ${ }^{2}$ Fujian Province University Key Laboratory of Green Energy and Environment Catalysis, College of Chemistry and Materials, Ningde \\ Normal University, Ningde, Fujian 352100, China \\ ${ }^{3}$ College of Chemistry and Chemical Engineering, Chongqing University, Chongqing, 400030, China
}

\begin{abstract}
Although fuel cell (FC) has been regarded as promising "green" power generator, the Pt-based catalysts in the FC hampered their further development for its high cost and scarcity. Direct methanol fuel cell (DMFC) as another kind of proton exchange membrane fuel cell (PEMFC) has been manifested that Pd also performs a certain activity for methanol oxidation reaction (MOR). To better know the mechanism of MOR, we present a DFT study on the first step reaction of MOR on the Pd(111). The results show that methanol prefers to physically adsorb on the $\mathrm{Pd}(111)$ through oxygen atom, while the dehydrogenated hydrogen atoms can adsorb either on face-cantered cubic (FCC) or hexagonal close packed (HCP) sites. The intermediate products will form a much stronger interaction with the $\operatorname{Pd}(111)$ since they contain more unsaturated bonds. The energy barrier of $\mathrm{O}-\mathrm{H}$ bond scission is most favourable, while the $\mathrm{C}-\mathrm{O}$ bond is unfavourable in the first step of MOR.
\end{abstract}

\section{Introduction}

With the increasing severity of environmental pollution and global energy crisis, fuel cells as "green" energy conversion systems have attracted more and more attentions. [1, 2] FC can convert chemical energy directly into electric energy, and the products contain no pollution products. DMFC can also offer remarkably higher energy utilization efficiency but emits only $\mathrm{CO}_{2}$. In addition, methanol can be synthesized by decomposing biomass fuel, which has abundant sources and lower energy consumption. However, the sluggish methanol oxidation kinetics is still an important issue, since the MOR is a complex reaction containing 6 electrons transference.

A better understanding of the reaction mechanism of MOR is of great significance to improve the reaction kinetics. Experimentally, research on the mechanism of MOR on the surface of transition metals was mainly focused on the single crystal surface under ultra-high vacuum conditions. And modern surface instruments have been used to study the exact broken bonds during MOR. Levis [3] observed the presence of methyl group on $\operatorname{Pd}(111)$ surface with $\mathrm{x}$-ray photoelectron spectroscopy (XPS). Guo [4] did not observe the broken $\mathrm{C}-\mathrm{O}$ bond with isotope method. While Kruse [5] found both $\mathrm{CH}_{3}$ and $\mathrm{CH}_{3} \mathrm{O}$ on the $\mathrm{Pd}(111)$ at the same time. Many scientists believe that $\mathrm{CH}_{\mathrm{x}} \mathrm{O}(\mathrm{x}=1-3)$ is produced only by $\mathrm{O}-\mathrm{H}$ bond breaking during methanol decomposition on Pd surface. However, Chen [6] considered that the dissociation of methanol is not only the above two processes, but may be carried out simultaneously or affected by the surface coverage. Theoretically, $\mathrm{Hu}$ [7] found that the $\mathrm{O}-\mathrm{H}$ bond breaking was much easier. Though the study on the mechanism of MOR has attracted much attention, the exact broken bond in the first step of MOR is still controversial. Thus, the adsorption of methanol, co-adsorption of its intermediate products, and the reaction energy barrier of the first step in MOR have been studied in this paper.

\section{Calculation model and method}

The PW91 method based on the generalized gradient approximation is used to calculate the exchange correlation energy. And the transition state is searched with linear synchronous transit (LST) method. A $2 \times 2$ three-layer $\operatorname{Pd}(111)$ is chosen as our slab model, and a vacuum of $11.23 \AA$ which is 5 times of Pd layer spacing is built to create a two-dimensional $\operatorname{Pd}(111)$ surface. The lower two layers are fixed at their optimized positions while the top atomic layer is thoroughly relaxed in all calculations. A Fermi surface smearing of 0.01 a.u. is utilized to speed up the convergence of k-point sampling. $\mathrm{K}$ point of the first brillouin zone is set to $4 \times 4 \times 1$. The adsorption energy is calculated according to the formula 1.

$$
E_{\text {ads }}=E_{\text {complex }}-\left(E_{P d}+E_{A}\right)
$$

$E_{\text {ads }}$ is the adsorption energy, $E_{\text {complex }}$ is the total energy of the system after species adsorption, $E_{P d}$ is the energy of clean $\mathrm{Pd}(111)$ surface, $\mathrm{E}_{\mathrm{A}}$ is the energy of adsorbed species.

\footnotetext{
* Corresponding author: lyx@yanan-motor.com
} 


\section{Results and discussion}

Adsorption is always the beginning step in every catalytic reaction. Herein, the adsorption of methanol and its intermediate products on $\operatorname{Pd}(111)$ are studied. And all the adsorptions at high symmetry sites on $\operatorname{Pd}(111)$ as shown in figure 1 are considered.

\subsection{Methanol adsorption}

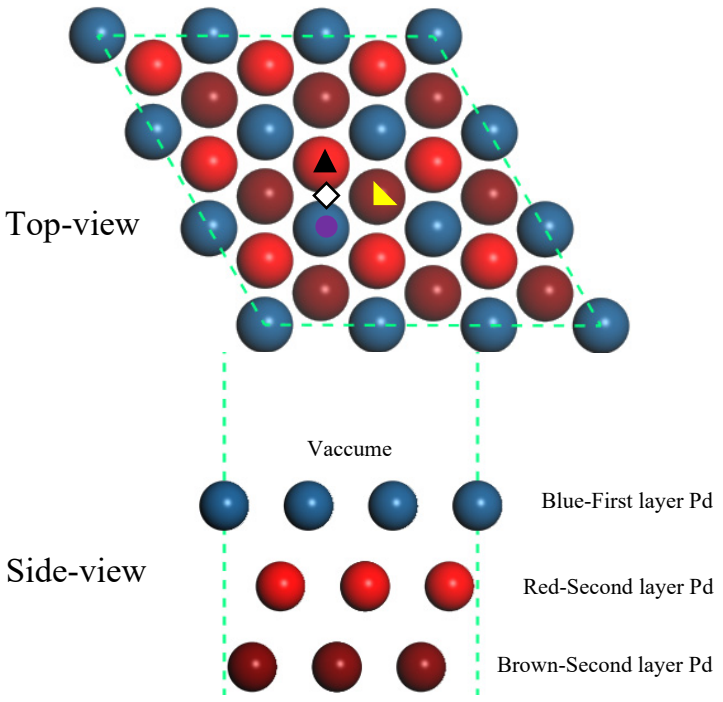

Figure 1. The high symmetry adsorption sites on $\mathrm{Pd}(111)$ ( $\Delta$ HCP site, $\quad$ FCC site, $\bigcirc$ Top site, $\diamond$ bridge site)

Table 1. The adsorption structures of methanol on $\operatorname{Pd}(111)$

\begin{tabular}{|c|c|c|c|c|}
\hline $\begin{array}{c}\text { Adsorption } \\
\text { Site }\end{array}$ & $\begin{array}{c}\text { dO-H } \\
(\AA)\end{array}$ & $\begin{array}{c}\text { dO-C } \\
(\AA)\end{array}$ & $\begin{array}{c}\text { do-Pd } \\
(\AA)\end{array}$ & $\begin{array}{c}\mathrm{d}_{\mathrm{C}-\mathrm{H}} \\
(\AA)\end{array}$ \\
\hline Free & 0.969 & 1.425 & --- & $1.078 ; 1.079 ; 1.079$ \\
\hline O-Top & 0.958 & 1.415 & 2.63 & $1.078 ; 1.084 ; 1.083$ \\
\hline O-FCC & 0.961 & 1.406 & 3.32 & $1.079 ; 1.074 ; 1.080$ \\
\hline O-HCP & 0.960 & 1.405 & 3.31 & $1.075 ; 1.078 ; 1.079$ \\
\hline $\begin{array}{c}\text { Parallel } \\
\rightarrow \text { Top* }\end{array}$ & 0.967 & 1.424 & 2.73 & $1.079 ; 1.081 ; 1.081$ \\
\hline $\mathrm{CH}_{3}-\mathrm{Top}$ & 0.956 & 1.411 & --- & $1.078 ; 1.085 ; 1.086$ \\
\hline $\mathrm{CH}_{3}$-FCC & 0.956 & 1.402 & --- & $1.079 ; 1.088 ; 1.088$ \\
\hline
\end{tabular}

* The original parallel adsorption mode changed to Top mode without any energy barrier.

Figure 1 shows the high symmetry sites on the $\operatorname{Pd}(111)$, the methanol and related intermediates products adsorbed on the sites are calculated in this paper. The possible adsorption modes of methanol either through $\mathrm{CH}_{3}$ or $\mathrm{OH}$ on the high symmetry sites of $\mathrm{Pd}(111)$ surface are calculated and the results are listed in table 1 and table 2. The bond length of $\mathrm{O}-\mathrm{H}$ in free methanol is $0.969 \AA$, and all the adsorption $\mathrm{OH}$ bonds decease a little bit. For the adsorption of methanol through the $\mathrm{O}$ atom, it is $0.958 \AA$ in the O-Top mode, while it becomes $0.961 \AA$ for the O-FCC mode and $0.960 \AA$ for the OHCP mode. It gets the largest value of $0.967 \AA$ when the original parallel mode turns to the O-top mode. For the adsorption of methanol through the $\mathrm{CH}_{3}$, it is $0.956 \AA$ for the $\mathrm{CH}_{3}$-Top mode and $\mathrm{CH}_{3}$-FCC mode as well. The parallel adsorptive mode will change to a top adsorptive mode with $\mathrm{OH}$ close to the $\mathrm{Pd}(111)$, which means that the top adsorptive mode with oxygen closed to the surface is energetically favourable. The bond length of $\mathrm{C}-\mathrm{O}$ in free methanol is $1.425 \AA$, and the $\mathrm{C}-\mathrm{O}$ bond ranges from $1.405 \AA$ to $1.415 \AA$ in the O-mode adsorption. While it is $1.411 \AA$ and $1.402 \AA$ for $\mathrm{CH}_{3}$-Top mode and $\mathrm{CH}_{3}-\mathrm{FCC}$ mode, respectively. For the distances between $\mathrm{O}$ of methanol and $\mathrm{Pd}$, it ranges from $2.63 \AA$ to $3.32 \AA$ except for the $\mathrm{CH}_{3}$ mode. All the $\mathrm{C}-\mathrm{H}$ bonds of the adsorbed methanol always keep the similar values with that in the free methanol, and the largest change can be obtained in the $\mathrm{CH}_{3}$-FCC mode.

Table 2. The adsorption energy $\left(E_{\mathrm{ads}}, \mathrm{kJ} / \mathrm{mol}\right)$ of methanol on $\operatorname{Pd}(111)$

\begin{tabular}{|c|c|c|c|c|c|}
\hline $\begin{array}{c}\text { Adsorption } \\
\text { Site }\end{array}$ & O-Top & O-FCC & O-HCP & C-Top & C-FCC \\
\hline $\begin{array}{c}\text { Eads } \\
(\mathrm{kJ} / \mathrm{mol})\end{array}$ & -38.20 & -25.13 & -25.04 & -23.62 & -25.43 \\
\hline
\end{tabular}

The adsorption energy of methanol on $\mathrm{Pd}(111)$ is also calculated. As listed in Table 2, the adsorption energy of methanol with O-Top mode is $-38.20 \mathrm{~kJ} / \mathrm{mol}$, which is energy most favourable. And it is $-23.62 \mathrm{~kJ} / \mathrm{mol}$ for the C-Top mode. The energy difference between each configuration is not very large, and the most favourable adsorption mode of methanol on $\operatorname{Pd}(111)$ is through $\mathrm{O}$ atom. Together with the structural properties listed in table 1, it can be found that three $\mathrm{C}-\mathrm{H}$ bonds of the most favourable adsorptive methanol are $1.079 \AA$, $1.081 \AA$ and $1.081 \AA$, respectively. A little elongation of $\mathrm{C}-\mathrm{H}$ bond can be observed compared with that of free methanol molecule. While the $\mathrm{O}-\mathrm{H}$ bond and $\mathrm{C}-\mathrm{O}$ bond become about $0.01 \AA$ shorter than the free methanol molecule. Compared with the original bonds in the free methanol molecule, all the distances between each atom almost keep its original value. This indicates that only physical adsorption occurs when methanol is adsorbed on $\operatorname{Pd}(111)$ surface. The weak interaction may lie in the $\mathrm{d}$ electrons of $\mathrm{Pd}$ and the lone pair electrons of $\mathrm{O}$ atom in methanol molecule.

\subsection{Hydrogen atom adsorption}

$\mathrm{H}$ atom is the main product of methanol dissociation. The adsorption of $\mathrm{H}$ atom at four high symmetry positions on $\operatorname{Pd}(111)$ surface is calculated in this section, and the results are listed in table 3 .

It can be found that $\mathrm{H}$ atom mainly adsorbs at $\mathrm{HCP}$ and FCC sites, and the $\mathrm{H}$ atom adsorbed at the bridge site will spontaneously move to the adjacent FCC sites during the optimization process. The adsorption energy of top $\mathrm{H}$ atom is $-227.75 \mathrm{~kJ} / \mathrm{mol}$, and the $\mathrm{Pd}-\mathrm{H}$ distance is $1.529 \AA$. It is about $40 \mathrm{~kJ} / \mathrm{mol}$ lower than that at both 
FCC and HCP sites. The average distance of $\mathrm{Pd}-\mathrm{H}$ distance at the FCC site is $0.932 \AA$, which is $0.012 \AA$ than that at HCP site. The covalent radii of hydrogen and Pd atom are $0.37 \AA$ and $1.23 \AA$, respectively. However, it can be found that the $\mathrm{Pd}-\mathrm{H}$ distances become even shorter than the covalent radii of $\mathrm{Pd}$ atoms. The significant shortened distance between $\mathrm{H}$ and $\mathrm{Pd}$ indicates that $\mathrm{H}$ and $\mathrm{Pd}$ have strong covalent interaction and form multiple hydrogen bonds, which should be the main reason for the energy reduction. Thus, the hydrogen atom is put on the FCC site when we perform the calculation of transition state search.

Table 3. The adsorption of $\mathrm{H}$ atom on $\mathrm{Pd}(111)$

\begin{tabular}{|c|c|c|c|c|}
\hline ads-site & Top & FCC* & HCP & FCC \\
\hline $\mathrm{d}_{\text {surf-H }}(\AA)$ & 1.529 & 0.934 & 0.944 & 0.932 \\
\hline Eads $(\mathrm{kJ} / \mathrm{mol})$ & -227.75 & -267.53 & -262.89 & -267.12 \\
\hline
\end{tabular}

* The original site of $\mathrm{H}$ before optimization was bridge site.

\subsection{Adsorption of other intermediate products}

The intermediate products through the $\mathrm{O}-\mathrm{H}, \mathrm{C}-\mathrm{H}$ and $\mathrm{C}-$ $\mathrm{O}$ bond scission are studied here, and the most stable configuration have been listed in table 4 and figure 2 . For the adsorption of methoxy through $\mathrm{O}-\mathrm{H}$ bond scission. The C-O bond axis is almost perpendicular to the Pd (111) surface with the $\mathrm{O}$ atom close to $\mathrm{Pd}(111)$. Compared with that in methanol, the oxygen in the methoxy has a larger electron density due to the lack of a hydrogen atom, which leads to a stronger interaction between methoxy and the d electrons of $\mathrm{Pd}$. This is also the reason why the interaction energy of $\mathrm{CH}_{3} \mathrm{O}$ with $\mathrm{Pd}$ is larger at the triple vacancy.

Table 4. The most favourable adsorption site and adsorption energy of intermediate products on $\operatorname{Pd}(111)$

\begin{tabular}{|c|c|c|c|c|}
\hline $\begin{array}{c}\text { intermediate } \\
\text { products }\end{array}$ & $\mathrm{CH}_{3} \mathrm{O}$ & $\mathrm{CH}_{2} \mathrm{OH}^{*}$ & $\mathrm{CH}_{3}$ & $\mathrm{OH}$ \\
\hline $\begin{array}{c}\text { Adsorption } \\
\text { site }\end{array}$ & $\mathrm{FCC}$ & $\begin{array}{c}\text { C-top } \\
\text { and O- } \\
\text { FCC }\end{array}$ & Top & Bridge \\
\hline Eads $(\mathrm{kJ} / \mathrm{mol})$ & -157.00 & -177.62 & -179.61 & -227.85 \\
\hline
\end{tabular}

* $\mathrm{CH}_{2} \mathrm{OH}$ adsorbs on $\mathrm{Pd}(111)$ through both $\mathrm{C}$ and $\mathrm{O}$ atoms.

For the adsorption of $\mathrm{CH}_{2} \mathrm{OH}$ through $\mathrm{C}-\mathrm{H}$ bond scission. The adsorption of $\mathrm{CH}_{2} \mathrm{OH}$ on the $\mathrm{Pd}(111)$ with the $\mathrm{C}-\mathrm{O}$ axis parallel to the $\mathrm{Pd}(111)$ surface. The adsorption energy is $-177.62 \mathrm{~kJ} / \mathrm{mol}$, which is about 20 $\mathrm{kJ} /$ mol more stable than that of methoxy.

For the adsorption of $\mathrm{CH}_{3}$ and $\mathrm{OH}$ through $\mathrm{C}-\mathrm{O}$ bond scission. $\mathrm{CH}_{3}$ prefers to adsorb on the top of $\mathrm{Pd}$ with an adsorption energy of $-179.61 \mathrm{~kJ} / \mathrm{mol}$, and the distance between $\mathrm{C}$ and $\mathrm{Pd}$ is $2.07 \AA$. OH prefers to adsorb on the bridge site of $\mathrm{Pd}(111)$, and the distance of O-Pd spacing is $2.15 \AA$.

a


b
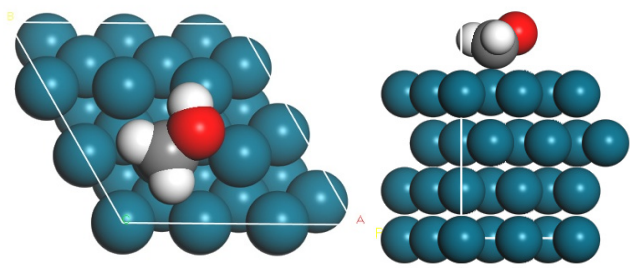

c
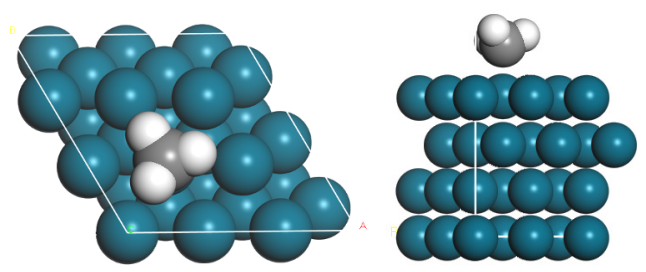

d


Figure 2. The most favourable adsorption structures of the intermediate products(a) $\mathrm{CH}_{3} \mathrm{O}$, (b) $\mathrm{CH}_{2} \mathrm{OH}$, (c) $\mathrm{CH}_{3}$, and (d) $\mathrm{OH}$ on Pd(111). (Red: Oxygen atom, Gray: Carbon atom, White: Hydrogen atom, Blue: Palladium atom. Left: top-view, Right: side-view)

\subsection{Reaction energy barrier}

The possible co-adsorptions of various intermediate products were optimized through putting the intermediates at their most favourable positions. Then we use the methanol adsorbed on $\operatorname{Pd}(111)$ as the initial state (IS), and optimized intermediate products coadsorbed on $\operatorname{Pd}(111)$ as the products to perform a transition state (TS) search. The calculated reaction energy barrier is listed in figure 3. It can be found that the $\mathrm{O}-\mathrm{H}$ bond scission will proceed easily while $\mathrm{C}-\mathrm{O}$ bond scission is unfavourable, since the energy barrier of $\mathrm{O}-\mathrm{H}$ bond scission is only $76.48 \mathrm{~kJ} / \mathrm{mol}$, while the energy barrier of C-O bond scission increases to 218.42 $\mathrm{kJ} / \mathrm{mol}$. The more the energy barrier, the more difficult 
the reaction proceeds. Furthermore, different reaction paths can be found for the bond scission of O-H. For the final state (FS) of co-adsorption of $\mathrm{CH}_{3} \mathrm{O}$ at the $\mathrm{FCC}$ site and $\mathrm{H}$ at the $\mathrm{HCP}$ site, a transition state with $\mathrm{CH}_{3} \mathrm{O}$ at the Top site and $\mathrm{H}$ at the HCP site can be determined, and this rout has the lowest energy barrier.



Figure 3. TS search for the dissociation of methanol in the first-step reaction

\section{Conclusions}

Methanol molecules only form weak physical adsorption on $\operatorname{Pd}(111)$ surface. The energy difference among each configurations is not very large, and the most favourable adsorption mode of methanol on $\mathrm{Pd}(111)$ is through $\mathrm{O}$ atom with an adsorption energy of $-38.20 \mathrm{~kJ} / \mathrm{mol}$. The $\mathrm{H}$ atom prefers to adsorbed at the FCC and HCP sites and the significant shortened distance between $\mathrm{H}$ and $\mathrm{Pd}$ indicates that $\mathrm{H}$ and $\mathrm{Pd}$ have strong covalent interaction and form multiple hydrogen bonds. The dissociative intermediate products of methanol usually form strong interaction with $\mathrm{Pd}(111)$ atoms because of the existence of unsaturated bonds. Compared with the $\mathrm{C}-\mathrm{O}$ bond scission, the $\mathrm{O}-\mathrm{H}$ bond broken on $\mathrm{Pd}(111)$ has a significantly smaller energy barrier, so it is considered that the first step breaking of methanol is mainly $\mathrm{O}-\mathrm{H}$ bond breaking.

\section{Acknowledgements}

This work was supported by the National Key R\&D Program of China (2017YFB0102900), the Academicindustry Cooperation Program of Ningde\&Xiamen
University, the Scientific Research Foundation of Ningde Normal University (2019ZX407, 2017ZDK08), the Foundation and Frontier Research Project of Chongqing of China (cstc2018jcyjAX0513), Science and Technology Research Program of Chongqing Municipal Education Commission (KJQN201801125)

\section{References}

1. J. Bo, C. Li, T. Jing, T. Takei, Y. Yamauchi, Angew. Chem. Int. Edit. 55, 10037( 2016)

2. G. Bai, C. Liu, Z. Gao. B. Lu, X. Tong, X. Guo, N. Yang, Small, 38, 1970202(2019)

3. R J Levis, Z. Jiang, N. Winograd. J. Am. Chem. Soc, 111, 4605(1989)

4. X. Guo, L. Hanley, J. T. Yates, et al. J. Am. Chem. Soc, 111, 3155(1989)

5. Kruse N, Robholz M, et al. Surf. Sci. 238, 95(1990)

6. J Chen, Z Jiang, Y Zhou, et al. Surf. Sci. 328, 248(1995)

7. C Zhang, P Hu. J. Chem. Phys, 115, 7182(2001) 